\title{
A Comparison of the Chemical Composition, In Vitro Bioaccessibility and Antioxidant Activity of Phenolic Compounds from Rice Bran and Its Dietary Fibres
}

\author{
Guanghe Zhao ${ }^{1,2} \mathbb{D}^{\mathbb{D}}$, Ruifen Zhang ${ }^{1,2, *}$, Lihong Dong ${ }^{1}$, Fei Huang ${ }^{1}$, Lei Liu ${ }^{1}$, Yuanyuan Deng ${ }^{1}$, \\ Yongxuan Ma ${ }^{1}$, Yan Zhang ${ }^{1}$, Zhencheng Wei ${ }^{1}$, Juan Xiao ${ }^{1}$ and Mingwei Zhang ${ }^{1, *}$ \\ 1 Sericultural \& Agri-Food Research Institute, Guangdong Academy of Agricultural Sciences/Key Laboratory \\ of Functional Foods, Ministry of Agriculture/Guangdong Key Laboratory of Agricultural Products \\ Processing, Guangzhou 510610, China; greatriver2007@163.com (G.Z.); dolify@163.com (L.D.); \\ hf1311@163.com (F.H.); liulei309@tom.com (L.L.); yuanyuan_deng@yeah.net (Y.D.); \\ mayongxuan@yahoo.cn (Y.M.); zhang_yan_@126.com (Y.Z.); zhencheng_wei@163.com (Z.W.); \\ xiaojuan209218@163.com (J.X.) \\ 2 College of Food Science \& Technology, Huazhong Agricultural University, Wuhan 430070, China \\ * Correspondence: ruifenzhang@163.com (R.Z.); mwzhh@vip.tom.com (M.Z.); \\ Tel.:+86-136-0903-8685 (R.Z.); +86-136-0900-8406 (M.Z.)
}

Received: 14 December 2017; Accepted: 16 January 2018; Published: 18 January 2018

\begin{abstract}
The composition, in vitro bioaccessibility and antioxidant activities of the phenolic compounds in defatted rice bran (DRB) and its soluble and insoluble dietary fibres were systematically evaluated in this study. The total phenolic content of insoluble dietary fibre from DRB (IDFDRB) was much higher than that of the soluble dietary fibre from DRB (SDFDRB) but was 10\% lower than that of DRB. Bound phenolics accounted for more than $90 \%$ of the total phenolics in IDFDRB, whereas they accounted for $34.2 \%$ and $40.5 \%$ of the total phenolics in DRB and SDFDRB, respectively. Additionally, the phenolic profiles and antioxidant activities were significantly different in DRB, SDFDRB and IDFDRB. The phenolic compounds in IDFDRB were much less bioaccessibility than those in DRB and SDFDRB due to the higher proportion of bound phenolics in IDFDRB. Considering that bound phenolics could be released from food matrices by bacterial enzymes in the large intestine and go on to exert significant beneficial health effects in vivo, further studies on IDFDRB are needed to investigate the release of the phenolics from IDFDRB via gut microbiota and the related health benefits.
\end{abstract}

Keywords: rice bran; dietary fibre; phenolic compounds; antioxidant activity; bioaccessibility

\section{Introduction}

Many studies in humans and experimental models have demonstrated the numerous health benefits associated with an increased intake of dietary fibre. These benefits include regulating body weight and insulin sensitivity, reducing the risk of coronary heart disease, alleviating metabolic syndrome, improving large bowel function, and preventing some cancers [1-3]. These health benefits may be closely related to the bioactive components bound to the dietary fibre, especially the active small molecule components such as phenolic compounds [4-6].

Recent reports have shown that bound phenolics, which are those phenolics that are mainly bound to the fibre, may give dietary fibre a range of physiological functions. Long-term intake of grape dietary fibre, which is rich in proanthocyanidins, improved lipid profiles and helped control blood pressure in adults [7], and acute intake of this kind of dietary fibre also increased the plasma antioxidant capacity of volunteers [5]. The consumption of carob fibre, which is rich in bound phenolics, lowered total and low density lipoprotein cholesterol in hypercholesterolemic subjects [8]. Furthermore, a diet 
containing cocoa fibre, which is also rich in bound phenolics, improved lipid profiles and reduced lipid peroxidation in hypercholesterolemic rats [9].

Fresh fruits and vegetables are usually thought to be rich in phenolic compounds, however, the total phenolic contents of whole grains are comparable to those of fruits and vegetables [10]. According to previous reports, most of the phenolics in whole grains distribute in the bran fractions [10-12], which are mostly constituted by dietary fibres (for example, accounting for more than $30 \%$ in rice bran). Furthermore, a higher proportion of the phenolic compounds is covalently bound to fibre matrix, compared with other matrixs in whole grains $[10,11]$. Therefore, we can deduce that the dietary fibre of rice bran is an important carrier of phenolics (especially bound phenolics) in rice.

The chemical composition and antioxidant activities of phenolics in brown rice and rice bran [13-19] and the influences of processing treatment on those parameters [20-26] have been reported in previous studies. Even though the majority of the phenolic components are widely reported to bind to the fibre matrix of grains, little is known about the chemical composition and antioxidant activities of the phenolics in rice bran dietary fibre. The differences in the phenolic profiles of rice bran and its soluble and insoluble dietary fibres are also unclear. The bioaccessibility of phenolic compounds in foods is a crucial factor affecting their biological activity, however, the bioaccessibility of the phenolics in dietary fibre has not been reported in the literature. Even though the bioaccessibility of the phenolic compounds in brown rice has been reported [27], significant differences in the chemical composition and the digestibility of the dietary fibre of rice bran and brown rice may lead to different release rates of the phenolic compounds during digestion. Therefore, the objectives of this study are to (1) compare the chemical composition and antioxidant activity of the phenolics in rice bran and its soluble and insoluble dietary fibres and (2) compare the bioaccessibility of the phenolic compounds in rice bran and its soluble and insoluble dietary fibres.

\section{Results and Discussion}

\subsection{Phenolic and Flavonoid Contents}

The free, bound and total phenolic and flavonoid contents in DRB and its dietary fibres were presented in Table 1. The bound and total phenolic contents and free, bound and total flavonoid contents in SDFDRB were the lowest, whilst the free phenolic content in IDFDRB was the lowest of the 3 analysed samples. When compared with IDFDRB, DRB had more free and total phenolics but fewer bound phenolics. The results of the flavonoid contents of DRB and IDFDRB were similar to those of the phenolics.

Table 1. Phenolic and flavonoid contents of defatted rice bran and its dietary fibres.

\begin{tabular}{cccc}
\hline & DRB & SDFDRB & IDFDRB \\
\hline Phenolics & & & \\
Free & $506.1 \pm 7.5 \mathrm{a} *(65.8) * *$ & $128.0 \pm 5.5 \mathrm{~b}(59.5)$ & $67.4 \pm 0.4 \mathrm{c}(10.0)$ \\
Bound & $263.6 \pm 9.8 \mathrm{~b}(34.2)$ & $87.3 \pm 0.6 \mathrm{c}(40.5)$ & $607.1 \pm 0.3 \mathrm{a}(90.0)$ \\
Total & $769.7 \pm 17.2 \mathrm{a}$ & $215.3 \pm 5.1 \mathrm{c}$ & $674.6 \pm 0.5 \mathrm{~b}$ \\
\hline Flavonoids & & & \\
Free & $305.3 \pm 11.7 \mathrm{a}(85.3)$ & $10.2 \pm 0.2 \mathrm{c}(51.5)$ & $113.1 \pm 2.8 \mathrm{~b}(41.7)$ \\
Bound & $52.8 \pm 5.6 \mathrm{~b}(14.7)$ & $9.6 \pm 0.2 \mathrm{c}(48.5)$ & $158.2 \pm 2.4 \mathrm{a}(58.3)$ \\
Total & $358.1 \pm 7.2 \mathrm{a}$ & $19.8 \pm 0.4 \mathrm{c}$ & $271.3 \pm 0.5 \mathrm{~b}$ \\
\hline
\end{tabular}

DRB, defatted rice bran. SDFDRB, soluble dietary fibre from DRB. IDFDRB, insoluble dietary fibre from DRB. * Values in the same line with no letters in common are significantly different among different samples $(p<0.05)$. ${ }^{* *}$ Values in parentheses indicate percentage contribution to the total content. ${ }^{A} \mathrm{mg} \mathrm{GAE} / 100 \mathrm{~g} \mathrm{DW} .{ }^{\mathrm{B}} \mathrm{mg} \mathrm{CE} / 100 \mathrm{~g}$ DW.

As shown in Table 1, 65.8\% and 85.3\% of phenolics and flavonoids existed in free form in DRB, respectively. Some free phenolics would undoubtedly be released into water and even degraded during the gelatinization and sequential enzyme hydrolysis processes, which could account for the obvious 
reduction in the free phytochemical content in IDFDRB compared to that of DRB. The retention of a small quantity of free phenolics and flavonoids was attributed to physical blocking and noncovalent binding of the fibrous matrix. Similarly, previous studies reported that free phenolics are more susceptible to losses due to hydrothermal treatment $[28,29]$. In contrast, the solvent nonextractable bound phytochemicals were believed to be more stable at high temperatures since they are covalently bound to macromolecules such as fibre and protein [30,31]. Due to the removal of starch and protein from the DRB, the content of bound phenolics and flavonoids in IDFDRB was increased from $263.6 \mathrm{mg}$ GAE/100 g DW and 52.8 mg CE/100 g DW to 607.1 mg GAE/100 g DW and 158.2 mg CE/100 $\mathrm{g}$ DW, respectively. The percentage contribution of bound phenolics and flavonoids to the total was therefore increased from $34.2 \%$ and $14.7 \%$ to $90.0 \%$ and $58.3 \%$, respectively. The removal of starch and protein also caused the SDFDRB had a lower content of free phenolics and flavonoids, whilst the percentage contributions of bound phenolics and flavonoids to the total in SDFDRB was 6.3\% and $33.8 \%$ higher than those of DRB, respectively. Based on the yields of SDF and IDF from DRB $(2.5 \%, 28.9 \%$, respectively), it could be deduced that the majority of the bound phenolics in DRB was conjugated to IDFDRB.

\subsection{Phenolic Composition}

Seventeen monomeric phenolic compounds were detected in DRB and its dietary fibres, namely, gallic acid, protocatechuic acid, chlorogenic acid, $p$-hydroxybenzonic acid, catechin, vanillic acid, caffeic acid, syringic acid, epicatechin, vanilline, $p$-coumaric acid, ferulic acid, sinapic acid, isoquercitrin, caffeic acid methyl, quercetin, and ferulic acid methyl. Additionally, four unidentified substances were deduced to be phenolic compounds according to their UV spectral data. Specifically, peak 3 may be a phenolic acid. The content of each of the 21 monomeric phenolics and percentage contribution of free and bound fractions to the total were presented in Table 2. (Supplementary Materials Figure S1).

Table 2. Phenolic profiles of defatted rice bran and its dietary fibres ( $\mu \mathrm{g} / \mathrm{g} D W)$.

\begin{tabular}{|c|c|c|c|c|}
\hline Phenolics & Varieties & Free Form & Bound Form & Total \\
\hline \multirow{3}{*}{ Gallic acid } & DRB & $5.1 \pm 0.5 *(100)$ & nd & $5.1 \pm 0.5^{*}$ \\
\hline & SDFDRB & $2.4 \pm 0.0(100)$ & nd & $2.4 \pm 0.0$ \\
\hline & IDFDRB & nd & nd & nd \\
\hline \multirow{3}{*}{ Protocatechuic acid } & DRB & $11.1 \pm 0.4(100)$ & nd & $11.1 \pm 0.4$ \\
\hline & SDFDRB & nd & $0.9 \pm 0.0(100)$ & $0.9 \pm 0.0$ \\
\hline & IDFDRB & nd & nd & nd \\
\hline \multirow{3}{*}{ Unknown (Peak 3) } & DRB & $138.0 \pm 4.9 \mathrm{a}(100)$ & nd & $138.0 \pm 4.9 \mathrm{a}$ \\
\hline & SDFDRB & $7.6 \pm 0.3 b(100)$ & nd & $7.6 \pm 0.3 b$ \\
\hline & IDFDRB & $5.5 \pm 0.2 c(100)$ & nd & $5.5 \pm 0.2 c$ \\
\hline \multirow{3}{*}{ Chlorogenic acid } & DRB & $10.4 \pm 1.4 *(100)$ & nd & $10.4 \pm 1.4$ * \\
\hline & SDFDRB & $6.1 \pm 0.0(100)$ & nd & $6.1 \pm 0.0$ \\
\hline & IDFDRB & nd & nd & nd \\
\hline \multirow{3}{*}{$p$-Hydroxybenzonic acid } & DRB & $\operatorname{Tr}$ & $\operatorname{Tr}$ & $\operatorname{Tr}$ \\
\hline & SDFDRB & nd & $0.2 \pm 0.0(100)$ & $0.2 \pm 0.0$ \\
\hline & IDFDRB & nd & $2.9 \pm 0.1 *(100)$ & $2.9 \pm 0.1 *$ \\
\hline \multirow{3}{*}{ Catechin } & DRB & $26.0 \pm 1.5 *(65.4)$ & $12.9 \pm 1.7(34.6)$ & $39.8 \pm 2.6 *$ \\
\hline & SDFDRB & $3.4 \pm 0.1(100)$ & nd & $3.4 \pm 0.1$ \\
\hline & IDFDRB & nd & nd & nd \\
\hline \multirow{3}{*}{ Vanillic acid } & DRB & $15.8 \pm 2.1 \mathrm{a}(62.2)$ & $9.3 \pm 0.6 b(37.8)$ & $25.5 \pm 2.1 \mathrm{a}$ \\
\hline & SDFDRB & $1.5 \pm 0.0 \mathrm{~b}(33.9)$ & $2.9 \pm 0.1 c(66.1)$ & $4.4 \pm 0.1 c$ \\
\hline & IDFDRB & $1.3 \pm 0.0 \mathrm{c}(9.9)$ & $11.3 \pm 0.3 \mathrm{a}(90.1)$ & $12.6 \pm 0.3 b$ \\
\hline \multirow{3}{*}{ Caffeic acid } & DRB & $\operatorname{Tr}$ & nd & $\operatorname{Tr}$ \\
\hline & SDFDRB & $0.3 \pm 0.0(15.8)$ & $1.6 \pm 0.0(84.2)$ & $1.8 \pm 0.0$ \\
\hline & IDFDRB & nd & nd & nd \\
\hline
\end{tabular}


Table 2. Cont.

\begin{tabular}{|c|c|c|c|c|}
\hline Phenolics & Varieties & Free Form & Bound Form & Total \\
\hline \multirow{3}{*}{ Syringic acid } & DRB & nd & $3.7 \pm 0.4 b(100)$ & $3.7 \pm 0.4 \mathrm{~b}$ \\
\hline & SDFDRB & $0.4 \pm 0.0(23.5)$ & $1.2 \pm 0.0 \mathrm{c}(76.5)$ & $1.5 \pm 0.0 \mathrm{c}$ \\
\hline & IDFDRB & nd & $4.8 \pm 0.0 \mathrm{a}(100)$ & $4.8 \pm 0.0 \mathrm{a}$ \\
\hline \multirow{3}{*}{ Epicatechin } & DRB & $79.7 \pm 7.4 *(60.9)$ & $50.8 \pm 1.0 *(39.1)$ & $130.8 \pm 8.5^{*}$ \\
\hline & SDFDRB & $11.0 \pm 0.3(28.2)$ & $28.1 \pm 0.3(71.8)$ & $39.1 \pm 0.6$ \\
\hline & IDFDRB & nd & nd & nd \\
\hline \multirow{3}{*}{ Vanilline } & DRB & $88.1 \pm 4.9 \mathrm{~b}(26.7)$ & $242.0 \pm 12.6 *(73.3)$ & $330.0 \pm 12.9 a$ \\
\hline & SDFDRB & $60.2 \pm 3.1 \mathrm{c}(84.1)$ & $11.4 \pm 0.2(15.9)$ & $71.5 \pm 2.9 c$ \\
\hline & IDFDRB & $103.0 \pm 2.4 a(100)$ & nd & $103.0 \pm 2.4 \mathrm{~b}$ \\
\hline \multirow{3}{*}{$p$-Coumaric acid } & DRB & $13.5 \pm 0.9 \mathrm{a}$ & $402.4 \pm 53.5 b(96.8)$ & $416.0 \pm 54.0 \mathrm{~b}$ \\
\hline & SDFDRB & $4.8 \pm 0.0 \mathrm{~b}(22.9)$ & $16.0 \pm 0.5 \mathrm{c}(77.1)$ & $20.8 \pm 0.5 c$ \\
\hline & IDFDRB & $2.90 \pm 0.1 \mathrm{c}(0.3)$ & $1098.6 \pm 5.2 \mathrm{a}(99.7)$ & $1101.5 \pm 5.2 \mathrm{a}$ \\
\hline \multirow{3}{*}{ Ferulic acid } & DRB & $26.1 \pm 2.8 \mathrm{a}(1.4)$ & $1784.9 \pm 131.8 b(98.6)$ & $1810.9 \pm 129.0 \mathrm{~b}$ \\
\hline & SDFDRB & $12.3 \pm 0.0 \mathrm{~b}(3.2)$ & $373.6 \pm 5.0 \mathrm{c}(96.8)$ & $385.9 \pm 5.0 c$ \\
\hline & IDFDRB & $2.4 \pm 0.2 \mathrm{c}(0.1)$ & $5124.3 \pm 39.4 a(99.9)$ & $5126.6 \pm 39.2 \mathrm{a}$ \\
\hline \multirow{3}{*}{ Sinapic acid } & DRB & $\operatorname{Tr}$ & nd & $\operatorname{Tr}$ \\
\hline & SDFDRB & nd & nd & nd \\
\hline & IDFDRB & nd & nd & nd \\
\hline \multirow{3}{*}{ Isoquercitrin } & DRB & $\mathrm{Tr}$ & $20.9 \pm 2.5 *(100)$ & $20.9 \pm 2.5 *$ \\
\hline & SDFDRB & $\mathrm{Tr}$ & $0.11 \pm 0.0(100)$ & $0.11 \pm 0.0$ \\
\hline & IDFDRB & $\operatorname{Tr}$ & $\operatorname{Tr}$ & $\operatorname{Tr}$ \\
\hline \multirow{3}{*}{ Caffeic acid methylester } & DRB & $2.1 \pm 0.2 *(20.6)$ & $8.4 \pm 0.7 \mathrm{a}(79.4)$ & $10.3 \pm 0.6 a$ \\
\hline & SDFDRB & $2.0 \pm 0.0(82.4)$ & $0.4 \pm 0.0 \mathrm{c}(17.6)$ & $2.4 \pm 0.0 \mathrm{c}$ \\
\hline & IDFDRB & nd & $5.2 \pm 0.1 \mathrm{~b}(100)$ & $5.2 \pm 0.1 \mathrm{~b}$ \\
\hline \multirow{3}{*}{ Unknown (Peak 17) } & DRB & nd & $42.4 \pm 1.1 \mathrm{~b}(100)$ & $42.4 \pm 1.1 \mathrm{~b}$ \\
\hline & SDFDRB & nd & $9.2 \pm 0.4 \mathrm{c}(100)$ & $9.2 \pm 0.4 \mathrm{c}$ \\
\hline & IDFDRB & nd & $362.6 \pm 10.8 \mathrm{a}(100)$ & $362.6 \pm 10.8 \mathrm{a}$ \\
\hline \multirow{3}{*}{ Unknown (Peak 18) } & DRB & nd & $472.9 \pm 11.4 b(100)$ & $472.9 \pm 11.4 \mathrm{~b}$ \\
\hline & SDFDRB & nd & $77.9 \pm 2.3 \mathrm{c}(100)$ & $77.9 \pm 2.3 c$ \\
\hline & IDFDRB & nd & $1553.8 \pm 40.7 \mathrm{a}(100)$ & $1553.8 \pm 40.7 \mathrm{a}$ \\
\hline \multirow{3}{*}{ Quercetin } & DRB & $\operatorname{Tr}$ & $0.7 \pm 0.1 *(100)$ & $0.7 \pm 0.1 *$ \\
\hline & SDFDRB & nd & $0.3 \pm 0.0(100)$ & $0.3 \pm 0.0$ \\
\hline & IDFDRB & $\operatorname{Tr}$ & $\operatorname{Tr}$ & $\operatorname{Tr}$ \\
\hline \multirow{3}{*}{ Unknown (Peak 20) } & DRB & $5.5 \pm 0.2 \mathrm{a}(8.9)$ & $56.6 \pm 2.6 b(91.1)$ & $62.1 \pm 2.3 b$ \\
\hline & SDFDRB & $3.8 \pm 0.1 \mathrm{c}(35.5)$ & $6.9 \pm 0.3 c(64.5)$ & $10.7 \pm 0.2 \mathrm{c}$ \\
\hline & IDFDRB & $4.5 \pm 0.2 b(1.9)$ & $236.3 \pm 7.2 \mathrm{a}(88.1)$ & $240.8 \pm 6.5 a$ \\
\hline \multirow{3}{*}{ Ferulic acid methylester } & DRB & $0.3 \pm 0.0(27.5)$ & $0.7 \pm 0.2 b(72.5)$ & $0.9 \pm 0.2 b$ \\
\hline & SDFDRB & $\operatorname{Tr}$ & $0.6 \pm 0.0 \mathrm{~b}(100)$ & $0.6 \pm 0.0 \mathrm{c}$ \\
\hline & IDFDRB & nd & $2.00 \pm 0.1 \mathrm{a}(100)$ & $2.0 \pm 0.1 \mathrm{a}$ \\
\hline \multirow{3}{*}{$\begin{array}{l}\text { Total monomeric } \\
\text { phenolics }\end{array}$} & DRB & $422.3 \pm 20.8 \mathrm{a}(12.2)$ & $3032.0 \pm 100.9 \mathrm{~b}(87.8)$ & $3454.4 \pm 98.7 b$ \\
\hline & SDFDRB & $115.6 \pm 19.2 b(17.9)$ & $531.2 \pm 5.5 \mathrm{c}(82.1)$ & $646.8 \pm 18.6 c$ \\
\hline & IDFDRB & $119.6 \pm 2.2 b(1.4)$ & $8401.7 \pm 128.3 a(98.6)$ & $8521.3 \pm 127.4 \mathrm{a}$ \\
\hline
\end{tabular}

DRB, defatted rice bran. SDFDRB, soluble dietary fibre from DRB. IDFDRB, insoluble dietary fibre from DRB. The unidentified phenolic compounds (peak 3,17, 18, 20) were caculated as ferulic acid equivalent. $\mathrm{Tr}$, $\mathrm{Trace}$; $\mathrm{nd}$, not detectable. Values with different letters or * in each column are significantly different among different samples $(p<0.05)$. Values in parentheses indicate percentage contribution to the total content.

The phenolic composition and contents of DRB, SDFDRB and IDFDRB were significantly different. All the 21 monomeric phenolics could be detected in DRB, although there were only traces of $p$-hydroxybenzonic acid, caffeic acid, and sinapic acid present. The findings were in agreement with previous reports [26,32]. For the dietary fibres, sinapic acid was not found in SDFDRB, and gallic acid, protocatechuic acid, chlorogenic acid, catechin, caffeic acid, epicatechin, and sinapic acid were not found in IDFDRB. Only 8 out of the 21 detected compounds, namely, vanillic acid, $p$-coumaric acid, ferulic acid, isoquercitrin and four unidentified substances, were present in DRB and both its dietary fibres. 
The unidentified phenolic acid (peak 3) was the primary free monomeric phenolic compound in DRB, while vanilline was the predominant free monomeric phenolic compound in SDFDRB and IDFDRB. Similarly, vanilline was the predominant free monomeric phenolic compound in foxtail millet dietary fibre [33]. Conversely, ferulic acid and $p$-coumaric acid were the major bound monomeric phenolic compounds in DRB and IDFDRB, and they totally accounted for $72.1 \%$ and $74.1 \%$ of their total bound monomeric phenolics, respectively. Similar results were found in earlier studies on rice bran [17,18]. However, vanillic acid [34,35] and hydroxybenzonic acid [15] were reported to be the major bound monomeric phenolics together with the predominant ferulic acid in rice bran. The discrepancies among these studies might be attributed to the differences in rice varieties, cultivating environments, etc. Ferulic acid was the major bound monomeric phenolic compound in SDFDRB, accounting for $70.3 \%$ of the total content of bound monomeric phenolics. Furthermore, more than $95 \%$ of the ferulic acid present in DRB, SDFDRB and IDFDRB was in bound form. Similar case was also reported in SDF and IDF of red rice [36]. Conversely, gallic acid and hesperidin were the major bound phenolic acids in mango peel dietary fibre [37] and citrus (Citrus junos Sieb. ex Tanaka) insoluble dietary fibre [38], respectively. Hence, the composition of bound phenolics in dietary fibre is mainly related to the source of the fibre.

The total bound monomeric phenolics measured by HPLC method accounted for $87.8 \%, 82.1 \%$ and $98.6 \%$ of the total content of monomeric phenolics in DRB, SDFDRB and IDFDRB, respectively. However, based on the Folin-Ciocalteu colorimetric method, bound phenolics accounted for $34.2 \%$, $40.5 \%$ and $90.0 \%$ of the contents of total phenolics in DRB, SDFDRB and IDFDRB, respectively. Many factors could partly explain this discrepancy among them, the complexity of the components of the bound fraction extracts and the nonspecificity of the Folin-Ciocalteu colorimetric method might be the major factors. The bound phenolic contents in DRB, SDFDRB and IDFDRB measured by the 2 methods were consistent with each other, but that was not the case for the free phenolic contents. The free phenolics in the samples were extracted with aqueous organic solvent. Inevitably, some reducing components, such as amino acids and reducing sugars, as well as ascorbic acid, could be extracted along with the free phenolics and react with Folin-Ciocalteu reagent, resulting in an over-estimation of the value $[39,40]$. Furthermore, owing to the dearth of essential technical data and standard substances, we failed to quantify those unidentified substances in free phenolics in DRB, SDFDRB and IDFDRB, resulting in an under-estimation of the value by the HPLC method. Additionally, due to its solubility, some SDFDRB itself may dissolve in the solvent when its free phenolics were extracted, which would lead to an over-estimation of the value by the Folin-Ciocalteu colourimetric method.

Apart from phenolic acids, 4 monomeric flavonoids, namely, catechin, epicatechin, isoquercitrin and quercetin, were also detected. There was a measurable amount of each of the 4 monomeric flavonoids in DRB and SDFDRB, but only trace or undetectable levels of these compounds in IDFDRB. Despite the possible presence of other unidentified flavonoids, phenolic acids are likely the predominant phenolic compounds bound to IDFDRB, which is in agreement with the results of other studies $[11,32,36]$. Some flavonoids bound to proteins or SDF in DRB may be removed during the enzymatic hydrolysis of the protein and the removal of SDF during the preparation of IDFDRB. Taken together, there were significant differences in both the phenolic composition and contents among DRB and its fibres.

\subsection{Antioxidant Capacity by FRAP, ORAC and CAA}

To better evaluate the potential antioxidant properties of DRB and its fibres, three assays, namely, FRAP (ferric reducing antioxidant power), ORAC (oxygen radical absorbance capacity) and CAA (cellular antioxidant activity) assays, were carried out in the present study. The obtained results were presented in Table 3.

As for the free fractions, DRB had the highest antioxidant capacity among the FRAP, ORAC and CAA assays followed by SDFDRB and IDFDRB. These results were in accordance with the phenolic 
contents among DRB and its fibres (Table 1). Furthermore, vanilline may be the major contributor to the antioxidant activity due to its high proportion in the free fractions of DRB and its fibres (Table 2). With regard to the bound fractions, IDFDRB showed the highest antioxidant activity by all 3 assays, followed by DRB and SDFDRB, which was in agreement with its higher content of bound phenolics. Presumably, $p$-coumaric acid and ferulic acid are the major contributors to the antioxidant activity due to their high proportion in the bound fraction of IDFDRB (Table 2). As with the total antioxidant activity, DRB possessed the highest FRAP and ORAC values, IDFDRB showed the highest CAA activity, and SDFDRB had the lowest values in all 3 assays.

Table 3. Antioxidant activities of defatted rice bran and its dietary fibres.

\begin{tabular}{cccc}
\hline Samples & Free & Bound & Total \\
\hline FRAP ${ }^{A}$ & & & \\
DRB & $34.7 \pm 0.1 \mathrm{a} *(72.0)^{* *}$ & $13.8 \pm 0.3 \mathrm{~b}(28.0)$ & $48.5 \pm 0.3 \mathrm{a}$ \\
SDFDRB & $4.1 \pm 0.1 \mathrm{~b}(47.0)$ & $4.6 \pm 0.1 \mathrm{c}(53.0)$ & $8.7 \pm 0.2 \mathrm{c}$ \\
IDFDRB & $3.7 \pm 0.0 \mathrm{c}(12.0)$ & $27.9 \pm 0.1 \mathrm{a}(88.0)$ & $31.6 \pm 0.2 \mathrm{~b}$ \\
\hline ORAC & & & \\
DRB & $228.5 \pm 15.7 \mathrm{a}(67.4)$ & $110.7 \pm 2.4 \mathrm{~b}(32.6)$ & $339.1 \pm 6.7 \mathrm{a}$ \\
SDFDRB & $23.0 \pm 0.3 \mathrm{~b}(32.6)$ & $47.5 \pm 0.5 \mathrm{c}(67.4)$ & $70.6 \pm 0.8 \mathrm{c}$ \\
IDFDRB & $17.2 \pm 1.1 \mathrm{~b}(8.9)$ & $178.9 \pm 8.7 \mathrm{a}(91.1)$ & $196.4 \pm 10.0 \mathrm{~b}$ \\
\hline CAA C & & & \\
DRB & $31.7 \pm 2.2 \mathrm{a}(22.9)$ & $106.7 \pm 14.2 \mathrm{~b}(77.1)$ & $138.5 \pm 12.2 \mathrm{~b}$ \\
SDFDRB & $12.3 \pm 0.2 \mathrm{~b}(15.7)$ & $66.0 \pm 0.4 \mathrm{c}(84.3)$ & $78.3 \pm 0.3 \mathrm{c}$ \\
IDFDRB & $3.0 \pm 0.1 \mathrm{c}(1.2)$ & $248.5 \pm 0.6 \mathrm{a}(98.8)$ & $251.3 \pm 0.3 \mathrm{a}$
\end{tabular}

$\mathrm{DRB}$, defatted rice bran. SDFDRB, soluble dietary fibre from DRB. IDFDRB, insoluble dietary fibre from DRB. * Values in the same column with no letters in common are significantly different among different samples $(p<0.05)$.

** Values in parentheses indicate percentage contribution to the total. ${ }^{\mathrm{A}} \mu \mathrm{mol} \mathrm{TE} / \mathrm{g} \mathrm{DW} .{ }^{\mathrm{B}} \mu \mathrm{mol} \mathrm{TE} / \mathrm{g} \mathrm{DW} .{ }^{\mathrm{C}} \mu \mathrm{mol}$ $\mathrm{QE} / 100 \mathrm{~g} \mathrm{DW}$.

As shown in Table 3, the FRAP value of the free fractions contributed more than $70 \%$ of the total FRAP value of DRB, but only $10 \%$ for IDFDRB. The ORAC values of the free fractions contributed more than $60 \%$ of the total ORAC value of DRB, but less than $40 \%$ and $10 \%$ to SDFDRB and IDFDRB, respectively. In contrast, the CAA values of the bound fractions contributed more than $70 \%, 80 \%$ and $90 \%$ of the total CAA values of DRB, SDFDRB and IDFDRB, respectively. Hence, the antioxidant activity of IDFDRB was mostly determined by its bound phenolics. Conversely, the free phenolics were the major contributors to the antioxidant activity (DPPH radical scavenging capacity and FRAP) of insoluble dietary fibre from citrus (Citrus junos Sieb. ex Tanaka) [38]. This discrepancy may be due to the difference in the phenolic composition and contents. The total antioxidnt activities of IDFDRB as evaluated by these three methods were 2-4 times greater than those of SDFDRB. Similarly, the IDF from red rice showed a DPPH radical scavenging activity nearly 17 times greater than that of the corresponding SDF [36].

\subsection{Bioaccessibility of the Phenolic Compounds in Rice Bran and Its Dietary Fibres}

Above data proved that DRB and its dietary fibres were rich in phenolic compounds. However, the consumption of foods containing abundant phenolic compounds does not usually mean that a substantial amount of active compounds will be absorbed by the human body [41,42]. The biological properties of phenolics may mostly depend on their release from the food matrix during digestion, which determines the bioaccessibility of the phenolic compounds. The bioaccessibility of a nutrient can be defined as the percentage of the nutrient released from the food matrix making it available for absorption through gastrointestinal mucosa after digestion [43]. Phenolic bioaccessibility directly influences the in vivo physiological function of these compounds. To date, there have been few studies involving the phenolic bioaccessibility of DRB and its dietary fibres. Hence, the bioaccessibility of the phenolic compounds in DRB and its dietary fibres were investigated in this study. 
Considering rice is usually consumed after being cooked, DBR was cooked by steaming for $20 \mathrm{~min}$ prior to being subjected to in vitro digestive tests. As shown in Table 4, the release of the phenolics in DRB and IDFDRB mainly occurred in the stomach, whereas the phenolics in SDFDRB were mainly released in the small intestine. The highest content of bioaccessible phenolics $(461.7 \mathrm{mg}$ GAE/100 g DW) after gastrointestinal digestion was observed in DRB followed by SDFDRB (188.1 mg GAE/100 g DW). Meanwhile, the highest phenolic bioaccessibility (87.4\%) was found in SDFDRB followed by DRB (60.0\%). IDFDRB had the least bioaccessible phenolics (126.9 mg GAE/100 $\mathrm{g}$ DW) and the lowest phenolic bioaccessibility $(18.8 \%)$. These results were consistent with previous studies $[44,45]$ that found that the SDF/IDF ratio in cereal products is positively correlated to their phenolic bioaccessibility. The phenolic bioaccessibility of IDFDRB was also much lower than those of nuts (56.87\%), vegetables (26.01\%), legumes (25.47\%) and fruits $(40.77 \%)$ and seven grains (Sorghum arundinaceum, Eleusinecorocana, Sorghum bicolor (red variety), Amaranthus hybridus, Rottboelliacochinchinensis, Panicum maximum and Brachiariabrizantha, average, 28\%) [46,47]. To our best knowledge, there have been no reports involving the phenolic bioaccessibility of dietary fibre from other materials.

Table 4. Phenolic bioaccessibility of defatted rice bran and its dietary fibres.

\begin{tabular}{cccc}
\hline Samples & $\begin{array}{c}\text { Total Phenlic Content } \\
\text { (mg GAE/100 g DW) }\end{array}$ & $\begin{array}{c}\text { Bioaccessible Phenolics after } \\
\text { GD (mg GAE/100 g DW) }\end{array}$ & $\begin{array}{c}\text { Bioaccessible Phenolics after } \\
\text { GID (mg GAE/100 g DW) }\end{array}$ \\
\hline DRB & $769.7 \pm 17.2 \mathrm{a} *$ & $443.2 \pm 22.5 \mathrm{a}(57.6) * *$ & $461.7 \pm 24.9 \mathrm{a}(60.0)$ \\
SDFDRB & $215.3 \pm 5.1 \mathrm{c}$ & $67.0 . \pm 0.7 \mathrm{c}(31.1)$ & $188.1 \pm 0.9 \mathrm{~b}(87.4)$ \\
IDFDRB & $674.6 \pm 0.5 \mathrm{~b}$ & $92.2 \pm 0.2 \mathrm{~b}(13.7)$ & $126.9 \pm 0.5 \mathrm{c}(18.8)$ \\
\hline
\end{tabular}

DRB, defatted rice bran. SDFDRB, soluble dietary fibre from DRB. IDFDRB, insoluble dietary fibre from DRB. $\mathrm{GD}$, gastric digestion. GID, gastrointestinal digestion. Total phenol content was calculated as the sum of free and bound phenolics. * Values in the same column with no letters in common are significantly different among different samples $(p<0.05) .{ }^{* *}$ Values in parentheses indicate the phenolic bioaccessibility, which was calculated as the percentage of bioaccessible phenolics after GD or GID to the total phenolics in samples.

Phenolic bioaccessibility are mostly determined by the existing form of the phenolic compounds. In fact, the higher free phenolic proportions in the above mentioned food materials accounted for their higher phenolic bioaccessibility. Free phenolics are compartmentalized primarily in vacuoles in the plant cells, whilst bound phenolics are mainly covalently bound to structural carbohydrates and proteins of the cell walls. During the digestion of food material, most of the free phenolics are released in the upper digestive tract by hydrolyzation by gut enzymes, whilst the bound phenolics are mostly released in the lower digestive tract by hydrolysation by a combination of gut enzymes and microbial enzymes [21,31]. Many researchers have reported that phenolics entering the lower digestive tract can have health benefits. A portion of the released phenolics are converted into lower molecular weight phenolics or metabolites that are subsequently absorbed into the blood through the epithelial cells of the gastrointestinal tract and then exert health benefits, however, some other phenolic compounds may contribute to maintaining a healthy, antioxidant environment by scavenging free radicals or offsetting the effects of dietary pro-oxidants together with the detained phenolics in the residue from food materials after digestion $[4,37,48,49]$. The low phenolic bioaccessibility of IDFDRB was mainly attributed to its higher proportion of bound phenolics. Hence, IDFDRB may exert important health benefits in the lower digestive tract.

\section{Materials and Methods}

\subsection{Chemical and Reagents}

Heat-stable $\alpha$-amylase (Termamyl 120 L, $120 \mathrm{KNU}-\mathrm{S} / \mathrm{mL}$ ), protease (Alcalase $2.4 \mathrm{~L}, 4.42 \mathrm{AU} / \mathrm{mL}$ ), and amyloglucosidase (AMG $300 \mathrm{~L}, 300 \mathrm{AGU} / \mathrm{mL}$ ) were purchased from Novozymes (Beijing, China) biotechnology Co., Ltd. Folin-Ciocalteu reagent, 6-hydroxy-2,5,7,8-tetramethylchroman-2carboxylic acid (Trolox), 2,4,6-tripyridyl-s-triazine (TPTZ), 3', $6^{\prime}$-dihydroxy-spiro[isobenzofuran-1 $\left({ }^{3} \mathrm{H}\right), 9^{\prime}$ - 
$\left({ }^{9} \mathrm{H}\right)$-xanthene]-3-one disodium salt (FL) and 2,2'-azobis-(2-amidinopropane) dihydrochloride (ABAP) were purchased from Sigma Chemical Co. (St. Louis, MO, USA). Gallic acid, chlorogenic acid, protocatechuic acid, $p$-hydroxybenzonic acid, vanillic acid, catechin, epicatechin, caffeic acid, sinapic acid, syringic acid, vanilline, isoquercitrin, $p$-coumaric acid, ferulic acid, quercetin, caffeic acid methyl, ferulic acid methyl were purchased from Aladdin Reagents (Shanghai, China). Fetal bovine serum (FBS), Hanks' balanced salt solution (HBSS) and Dulbecco's modified eagle's medium (DMEM) were purchased from Atlanta Biologicals (Lawrenceville, GA, USA), GibcoLife Technologies (Grand Island, NY, USA) and Thermo Fisher Scientific (Waltham, MA, USA), respectively. HepG2 human liver cancer cells were purchased from the American Type Culture Collection (ATCC) (Rockville, MD, USA). All other chemicals used were of analytical grade or above.

\subsection{Rice Grain Samples and Sample Preparation}

The rice grains used in this study were obtained from the experimental farm of Guangdong Academy of Agricultural Sciences, China. The rice grains were grown in the 2015 season, harvested directly from fields in July 2016, and air-dried until their moisture content was reduced to approximately $12 \%$. Then, they were dehusked and polished using a Satake Rice Machine (Satake Co., Hiroshima, Japan) to obtain approximately $10 \%(w / w)$ of fresh rice bran. Freshly prepared rice bran was sieved by passage through an 80 -mesh sieve and stored at $-20^{\circ} \mathrm{C}$ until analysis.

\subsection{Preparation of the Defatted Rice Bran and Its Dietary Fibres}

Defatted rice bran (DRB) was obtained by extracting fresh rice bran three times with 10-volume hexane at ambient temperature for $24 \mathrm{~h}$ under constant shaking to remove lipids. Freshly prepared DRB was ground and sieved by passage through an 80-mesh sieve. The soluble dietary fibre from DRB (SDFDRB) and insoluble dietary fibre from DRB (IDFDRB) were prepared based on the following procedures. Briefly, $60 \mathrm{~g}$ of DRB was mixed with $600 \mathrm{~mL}$ of distilled water and gelatinized at $95^{\circ} \mathrm{C}$ for $10 \mathrm{~min}$. Gelatinized DRB was subjected to sequential enzymatic digestion with $\alpha$-amylase $(1.8 \mathrm{~mL}$, $\left.\mathrm{pH} 6.0,95^{\circ} \mathrm{C}, 20 \mathrm{~min}\right)$, alcalase protease $\left(3.0 \mathrm{~mL}, \mathrm{pH} 7.5,60^{\circ} \mathrm{C}, 60 \mathrm{~min}\right)$ and amyloglucosidase $(1.2 \mathrm{~mL}$, $\left.\mathrm{pH} 4.5,60^{\circ} \mathrm{C}, 30 \mathrm{~min}\right)$ in a water bath to remove the starch and protein. After centrifugation $(6800 \times \mathrm{g}$, $10 \mathrm{~min}$ ), the residue was washed twice with distilled water at $60^{\circ} \mathrm{C}$, and then dried at $40^{\circ} \mathrm{C}$ for $24 \mathrm{~h}$ to yield IDFDRB. The supernatant was combined with the washings of the residue, and the mixture was gently neutralized by $10 \%(\mathrm{~m} / \mathrm{v}) \mathrm{Ca}(\mathrm{OH})_{2}$ to precipitate phytic acid. The mixture was then dialyzed (10 kDa molecular weight cut-off (MWCO) membrane) at $25^{\circ} \mathrm{C}$ for $24 \mathrm{~h}$ to desalt. The fraction failed to dialysis was concentrated to $1 / 4$ of its original volume at $45^{\circ} \mathrm{C}$ and precipitated by adding 4-volume ethanol overnight. It was then freeze-dried in a FDU-2110 freeze dryer (Tokyo physical and Chemical Corporation) for $72 \mathrm{~h}$ to yield SDFDRB. The dried materials were ground into a fine powder to pass an 80 -mesh sieve. All samples were stored at $-20^{\circ} \mathrm{C}$ until analysis.

\subsection{Chemical Composition}

Samples were analysed in triplicate for their moisture, starch, fat, crude protein $(\mathrm{N} \times 5.95)$ and ash contents according to AOAC (2005) methods 934.01 (gravimetric method), 978.10 (enzyme hydrolysis method), 948.22 (using aSoxhlet apparatus and petroleum ether), 960.52 (Kjeldahl method) and 942.05 (incineration at $525^{\circ} \mathrm{C}$ ), respectively. Chemical composition of DRB and its dietary fibres can be seen in Table 5. 
Table 5. Chemical composition of defatted rice bran and its dietary fibres.

\begin{tabular}{cccc}
\hline & DRB & SDFDRB & IDFDRB \\
\hline Water (\%) & $13.0 \pm 0.2$ & nd & $11.0 \pm 0.1$ \\
Starch (\%) & $30.5 \pm 1.2$ & $2.8 \pm 0.0$ & $4.9 \pm 0.0$ \\
Fat (\%) & Tr & nd & nd \\
Protein (\%) & $13.8 \pm 0.4$ & $12.2 \pm 0.2$ & $9.8 \pm 0.2$ \\
Ash (\%) & $10.1 \pm 0.3$ & $8.6 \pm 0.1$ & $4.5 \pm 0.1$ \\
\hline
\end{tabular}

DRB, defatted rice bran. SDFDRB, soluble dietary fibre from DRB. IDFDRB, insoluble dietary fibre from DRB. nd, not detectable. Tr, Trace.

\subsection{Extraction of Free Phenolics}

The free phenolic compounds were extracted by the method reported previously [50] with some modifications. Briefly, $1.0 \mathrm{~g}$ of DRB or its dietary fibre was blended with $50 \mathrm{~mL}$ of chilled $80 \%$ acetone at 10,000 rpm for $5 \mathrm{~min}$ in an ice bath. Then, the supernatant was separated by centrifugation at $8000 \times g$ for $10 \mathrm{~min}$, and the extraction procedure was repeated once. The two supernatants were combined and evaporated at $45^{\circ} \mathrm{C}$ under vacuum and reconstituted to a final volume of $10 \mathrm{~mL}$ with chilled $\mathrm{MeOH}$. The solution was then stored at $-20{ }^{\circ} \mathrm{C}$ until further analysis.

\subsection{Extraction of Bound Phenolics}

Bound phenolics were extracted by the method reported in previous studies [51]. Briefly, the residue from the extraction of the free phenolics was digested with $40 \mathrm{~mL}$ of $2 \mathrm{M} \mathrm{NaOH}$ at room temperature. The mixture was continuously shaken for $1 \mathrm{~h}$ under a nitrogen atmosphere. Then, the mixture was neutralized with concentrated hydrochloric acid and extracted 5 times with ethyl acetate. The pooled ethyl acetate supernatants were evaporated and reconstituted with chilled $\mathrm{MeOH}$ to a final volume of $10 \mathrm{~mL}$, and the solution was then stored at $-20^{\circ} \mathrm{C}$ until analysis.

\subsection{Determination of the Phenolic Content}

The phenolic content was determined using the method reported previously [52]. Briefly, $0.125 \mathrm{~mL}$ of the extracts was sequentially mixed with $0.5 \mathrm{~mL}$ of distilled water and $0.125 \mathrm{~mL}$ of Folin-Ciocalteu reagent. After letting the mixture react for $6 \mathrm{~min}, 1.25 \mathrm{~mL}$ of $7 \%$ aqueous $\mathrm{Na}_{2} \mathrm{CO}_{3}$ and $1.0 \mathrm{~mL}$ of water were sequentially added to the mixture. The final mixture was kept in the dark at room temperature for $90 \mathrm{~min}$, and then its absorbance was measured at $760 \mathrm{~nm}$. A standard curve was constructed by using gallic acid as the standard. The final results were expressed as $\mathrm{mg}$ of gallic acid equivalents (GAE) per $100 \mathrm{~g}$ dry weight (DW) of sample.

\subsection{Determination of the Flavonoid Content}

The flavonoid content was determined by the method reported previously [52]. Briefly, a $0.3 \mathrm{~mL}$ of the above extracts was sequentially mixed with $1.5 \mathrm{~mL}$ of distilled water and $0.09 \mathrm{~mL}$ of $5 \% \mathrm{NaNO}_{2}$ solution. Six min later, $0.18 \mathrm{~mL}$ of $10 \% \mathrm{AlCl}_{3} \cdot 6 \mathrm{H}_{2} \mathrm{O}$ solution was added to the mixture. Five min later, $0.6 \mathrm{~mL}$ of $1 \mathrm{M} \mathrm{NaOH}$ solution and $0.33 \mathrm{~mL}$ of distilled water were sequentially added. The absorbance of the final mixture was immediately determined at $510 \mathrm{~nm}$. A standard curve was constructed by using catechin as the standard. The final results were expressed as $\mathrm{mg}$ of catechin equivalents (CE) per $100 \mathrm{~g}$ dry weight (DW) of sample.

\subsection{Determination of the Phenolic Compositions}

Prior to HPLC analysis, all samples were passed through a $0.25 \mu \mathrm{m}$ membrane filter (Millipore, Billerica, MA, USA). Phenolic compositions were measured according to the procedure reported previously [53] with some modifications. Briefly, a $20 \mu \mathrm{L}$ aliquot was analysed using an Agilent 1260 HPLC system (Waldbronn, Germany) equipped with a DAD detector and a Zorbax SB-C18 
analytical column $(250 \times 4.6 \mathrm{~mm}$, i.d., $5 \mu \mathrm{m}$; Palo Alto, CA, USA). The mobile phase consisted of $0.4 \%$ aqueous acetic acid (solvent $\mathrm{A}$ ) and acetonitrile (solvent $\mathrm{B}$ ) at a flow rate of $1.0 \mathrm{~mL} / \mathrm{min}$. The column temperature was $25{ }^{\circ} \mathrm{C}$. Gradient elution was performed as follows: from 0 to 40 min, linear gradient from $5 \%$ to $25 \%$ solution B; from 40 to $45 \mathrm{~min}$, linear gradient from $25 \%$ to $35 \%$ solution B; from 45 to $50 \mathrm{~min}$, linear gradient from $35 \%$ to $50 \%$ solution B; and from 50 to 55 min, linear gradient from $50 \%$ to $5 \%$ solution B. Simultaneous monitoring was set at $280 \mathrm{~nm}$ for the quantification of monomeric phenolics. Based on the previous reports [17-19,26,32,34-36,53], the phenolic compounds in the samples were identified by comparing their experimental retention times and UV spectral data with those of known authentic standards.

\subsection{Antioxidant Activity Determined by FRAP Assay}

The FRAP assay was carried out according to the method reported previously [54]. The working solution was freshly prepared by mixing $25 \mathrm{~mL}$ of $300 \mathrm{mM}$ acetate buffer $\left(3.1 \mathrm{~g}\right.$ of $\mathrm{CH}_{3} \mathrm{COONa}_{3} 3 \mathrm{H}_{2} \mathrm{O}$ and $16 \mathrm{~mL}$ of $\mathrm{CH}_{3} \mathrm{COOH}$ per litre of buffer solution, $\left.\mathrm{pH} 3.6\right), 2.5 \mathrm{~mL}$ of $10 \mathrm{mM}$ TPTZ solution (3.12 $\mathrm{g}$ TPTZ per litre of $40 \mathrm{mM} \mathrm{HCl}$ ), and $2.5 \mathrm{~mL}$ of $20 \mathrm{mM} \mathrm{FeCl} 3 \cdot 6 \mathrm{H}_{2} \mathrm{O}$ solution and incubating the solution at $37^{\circ} \mathrm{C}$ for $10 \mathrm{~min}$ prior to use. A $0.09 \mathrm{~mL}$ of the diluted extract was vigorously mixed with $2.0 \mathrm{~mL}$ of the above working solution for $1 \mathrm{~min}$ and then placed in the dark for $60 \mathrm{~min}$. The absorbance was then measured at $593 \mathrm{~nm}$. Trolox was used to prepare a standard curve, and the FRAP antioxidant activity was expressed as $\mu \mathrm{mol}$ of Trolox equivalents per $\mathrm{g}$ DW of sample.

\subsection{Antioxidant Activity Determined by ORAC Assay}

The ORAC assay was carried out by the method reported previously [55]. The determination was performed using black-walled 96-well plates. Each well was sequentially charged with $20 \mu \mathrm{L}$ of diluted extracts or Trolox standard at concentrations ranging from 6.25 to $50 \mu \mathrm{M}$ and $200 \mu \mathrm{L}$ of fluorescein (final concentration $0.96 \mu \mathrm{M})$. The mixtures were incubated at $37^{\circ} \mathrm{C}$ for $20 \mathrm{~min}$, and then $20 \mu \mathrm{L}$ of $119 \mathrm{mM}$ ABAP was added to each well. Finally, the fluorescence intensity was measured using a Fluoroskan Ascent FL plate-reader (Tecan Infinite 200, Männedorf, Austria) at an excitation wavelength of $485 \mathrm{~nm}$ and an emission wavelength of $538 \mathrm{~nm}$ every $4.5 \mathrm{~min}$ for a total of 35 measurements. The results were expressed as $\mu \mathrm{mol}$ Trolox equivalents per $\mathrm{g}$ DW of sample.

\subsection{Antioxidant Activity Determined by CAA Assay}

Prior to the CAA determination, the phenolic extracts were evaporated and reconstituted with isopyknic distilled water. The CAA assay was performed according to the method previously reported [56]. Briefly, HepG2 cells were inoculated at a density of $6 \times 10^{4}$ per well in a 96-well black-walled microplate in $100 \mu \mathrm{L}$ of growth medium (DMEM containing $10 \% \mathrm{FBS}$ ), and cultivated in a $\mathrm{CO}_{2}$ incubator at $37{ }^{\circ} \mathrm{C}$ for $24 \mathrm{~h}$. After removing the medium and rinsing with PBS, the seeded wells were treated for $1 \mathrm{~h}$ with DMEM containing $25 \mu \mathrm{M}$ DCFH-DA with or without phenolic extracts. Subsequently, $600 \mu \mathrm{M}$ ABAP in $100 \mu \mathrm{L}$ of HBSS was added to each well except for the blank wells. The fluorescence of each well (excitation at $485 \mathrm{~nm}$, emission at $538 \mathrm{~nm}$ ) was measured by a Fluoroskan Ascent FL plate reader (Tecan Infinite 200, Männedorf, Austria) every 5 min for a total of 12 measurements. The results were reported as $\mu \mathrm{mol}$ quercetin equivalents (QE) per $100 \mathrm{~g} \mathrm{DW}$ of sample.

\subsection{Bioaccessibility of the Phenolic Compounds in Different Samples}

The bioaccessible phenolics were determined by an in vitro gastrointestinal digestion method following a previously reported procedure [57] with some modifications. Briefly, $1.5 \mathrm{~g}$ of DRB or its dietary fibre was placed in a $100 \mathrm{~mL}$ vessel, mixed with $30 \mathrm{~mL}$ of distilled water and heated in a water bath at $37^{\circ} \mathrm{C}$. A $1.5 \mathrm{~mL}$ aliquot of pepsin $(20 \mathrm{~g} / \mathrm{L}$ in $0.1 \mathrm{M} \mathrm{HCl})$ was then added into the vessel, and the $\mathrm{pH}$ was adjusted to 2.0 with $6 \mathrm{M} \mathrm{HCl}$. The gastric digestion was carried out for $1 \mathrm{~h}$. The $\mathrm{pH}$ of the mixture was then adjusted to 7.2 with $1 \mathrm{M} \mathrm{NaHCO}_{3}$ to stop gastric digestion. Intestinal 
digestion was initiated by sequentially adding $7.5 \mathrm{~mL}$ of pancreatin/bile solution $(2 \mathrm{~g} / \mathrm{L}$ of pancreatin and $12 \mathrm{~g} / \mathrm{L}$ of bile salt in $\left.0.1 \mathrm{M} \mathrm{NaHCO}_{3}\right)$ and $7.5 \mathrm{~mL}$ of $\mathrm{KCl} / \mathrm{NaCl}(120 \mathrm{mM} \mathrm{NaCl}$ and $5 \mathrm{mM} \mathrm{KCl})$, and digestion was continued for $2.5 \mathrm{~h}$. The supernatant was obtained by centrifugation at $6000 \times g$ for $10 \mathrm{~min}$ at $4{ }^{\circ} \mathrm{C}$ and then purified by precipitation by adding 4 -volume ethanol to remove SDF. The phenolic bioaccessibility was calculated as the percentage of bioaccessible phenolics present in the purified supernatant relative to the total phenolic content in DRB or its dietary fibre. A blank (without added DRB or its dietary fibre) was incubated under the same conditions, and its phenolic content was determined to correct for interferences from the digestion processes. The vessel was magnetically stirred during all the digestion processes.

\subsection{Statistical Analyses}

All treatments were conducted in triplicate, and the results were reported as the mean \pm SD. Statistical analysis was carried out using the IBM SPSS Statistic Version 20.0 software. Data were analysed by ANOVA, and the differences between means were assessed by Dunnett's tests or $t$ tests. A value of $p<0.05$ was considered to be significantly different. During the analysis of phenolic composition, when a compound could be detected only in 2 of the 3 samples, the $t$-test was used to evaluate the statistical difference between the contents.

\section{Conclusions}

This study revealed that IDFDRB had a higher proportion of bound phenolics and higher CAA activity than DRB and SDFDRB. However, IDFDRB showed lower phenolic bioaccessibility than DRB and SDFDRB. Bound phenolics are likely released from food matrix in the colon by the action of gut microbiota and may exert significant beneficial health effect in vivo. The release of the phenolics from IDFDRB in vivo and the related health effects require further investigation.

Supplementary Materials: Supplementary materials are available online.

Acknowledgments: This work was supported by the State key research and development plan (No. 2017YFD0400205-02, 2017YFD0401105), the Group Program of Natural Science Foundation of Guangdong Province (2016A030312001), the National Nature Science Foundation of China (31501478) and the Special Fund for Modern Agricultural Industry Technology System of Guangdong Province (2017LM1084).

Author Contributions: Mingwei Zhang designed the research. Guanghe Zhao performed the experiments and wrote the paper. Ruifen Zhang contributed to the revisions of the manuscript. Lihong Dong, Fei Huang and Lei Liu helped to perform the experiments. Yuanyuan Deng, Yongxuan Ma, Yan Zhang, Juan Xiao and Zhencheng Wei participated in analyzing data.

Conflicts of Interest: The authors declare not conflict of interest.

\section{References}

1. Galisteo, M.; Duarte, J.; Zarzuelo, A. Effects of dietary fibers on disturbances clustered in the metabolic syndrome. J. Nutr. Biochem. 2008, 19, 71-84. [CrossRef] [PubMed]

2. Elleuch, M.; Bedigian, D.; Roiseux, O.; Besbes, S.; Blecker, C.; Attia, H. Dietary fiber and fiber-rich by-products of food processing: Characterisation, technological functionality and commercial applications: A review. Food Chem. 2011, 124, 411-421. [CrossRef]

3. Mudgil, D.; Barak, S. Composition, properties and health benefits of indigestible carbohydrate polymers as dietary fiber: A review. Int. J. Biol. Macromol. 2013, 61, 1-6. [CrossRef] [PubMed]

4. Vitaglione, P.; Napolitano, A.; Fogliano, V. Cereal dietary fiber: A natural functional ingredient to deliver phenolic compounds into the gut. Trends Food Sci. Technol. 2008, 19, 451-463. [CrossRef]

5. Pérez-Jiménez, J.; Serrano, J.; Tabernero, M.; Arranz, S.; Díaz, M.E.; García, L.; Goñi, I.; Saura, F. Bioavailability of phenolic antioxidants associated with dietary fiber: Plasma antioxidant capacity after acute and long-term intake in humans. Plant Foods Hum. Nutr. 2009, 64, 102-107. [CrossRef] [PubMed]

6. Lattimer, J.M.; Haub, M.D. Effects of dietary fiber and its components on metabolic health. Nutrients 2010, 2, 1266-1289. [CrossRef] [PubMed] 
7. Pérez-Jiménez, J.; Serrano, J.; Tabernero, M.; Arranz, S.; Díaz, M.E.; García, L.; Goñi, I.; Saura, F. Effects of grape antioxidant dietary fiber in cardiovascular disease risk factors. Nutrition 2008, 24, 646-653. [CrossRef] [PubMed]

8. Ruiz-Rose, B.; Quintela, J.C.; Fuente, E.D.L.; Haya, J.; Perez-Olletos, L. Insoluble carob fiber rich in polyphenols lowers total and LDL cholesterol in hypercholesterolemic subjects. Plant Foods Hum. Nutr. 2010, 65, 50-56. [CrossRef] [PubMed]

9. Lecumberri, E.; Goya, L.; Mateos, R.; Alia, M.; Ramos, S.; Izquierdo-Pulido, M.; Bravo, L. A diet rich in dietary fiber from cocoa improves lipid profile and reduces malondialdehyde in hypercholesterolemic rats. Nutrition 2007, 23, 332-341. [CrossRef] [PubMed]

10. Liu, R.H. Whole grain phytochemicals and health. J. Cereal Sci. 2007, 46, 207-219. [CrossRef]

11. Adom, K.K.; Liu, R.H. Antioxidant activity of grains. J. Agric. Food Chem. 2002, 50, 6182-6187. [CrossRef] [PubMed]

12. Adom, K.K.; Sorrells, M.E.; Liu, R.H. Phytochemicals and Antioxidant Activity of Milled Fractions of Different Wheat Varieties. J. Agric. Food Chem. 2005, 53, 2297-2306. [CrossRef] [PubMed]

13. Nam, S.H.; Choi, S.P.; Kang, M.Y.; Koh, H.J.; Kozukue, N.; Friedman, N. Antioxidative activities of bran extracts from twenty one pigmented rice cultivars. Food Chem. 2006, 94, 613-620. [CrossRef]

14. Devi, R.R.; Jayalekshmy, A.; Arumughan, C. Antioxidant efficacy of phytochemical extracts from defatted rice bran in in-vitro model emulsions. Int. J. Food Sci. Technol. 2008, 43, 878-885. [CrossRef]

15. Laokuldilok, T.; Shoemaker, C.F.; Jongkaewwattana, S.; Tulyathan, V. Antioxidants and antioxidant activity of several pigmented rice brans. J. Agric. Food Chem. 2011, 59, 193-199. [CrossRef] [PubMed]

16. Jun, H.; Song, G.; Yang, E.; Youn, Y.; Kim, Y. Antioxidant activities and phenolic compounds of pigmented rice bran extracts. J. Food Sci. 2012, 77, C759-C764. [CrossRef] [PubMed]

17. Ti, H.H.; Li, Q.; Zhang, R.F.; Zhang, M.W.; Deng, Y.Y.; Wei, Z.C.; Chi, J.W.; Zhang, Y. Free and bound phenolic profiles and antioxidant activity of milled fractions of different indicarice varieties cultivated in southern China. Food Chem. 2014, 159, 166-174. [CrossRef] [PubMed]

18. Begum, A.; Goswami, A.; Chowdhury, P. A comparative study on free and bound phenolic acid content and their antioxidant activity in bran of rice (Oryza sativa L.) cultivars of Eastern Himalayan range. Int. J. Food Sci. Technol. 2015, 50, 2529-2536. [CrossRef]

19. Ti, H.H.; Guo, J.J.; Zhang, R.F.; Wei, Z.C.; Liu, L.; Bai, Y.J.; Zhang, M.W. Phenolic profiles and antioxidant activity in four tissue fractions of whole brown rice. RSC Adv. 2015, 7, 4984-4992. [CrossRef]

20. Verardo, V.; Gómez-Caravaca, A.M.; Marconi, E.; Segura-Carretero, A.; Garrido-Frenich, A.; Fernández-Gutiérrez, A. Determination of lipophilic and hydrophilic bioactive compounds in raw and parboiled rice bran. RSC Adv. 2016, 6, 50786-50796. [CrossRef]

21. Wang, T.; Chen, G.B. Improving bioaccessibility and bioavailability of phenolic compounds in cereal grains through processing technologies: A concise review. J. Funct. Foods 2014, 7, 101-111. [CrossRef]

22. Schmidt, C.G.; Gonçalves, L.M.; Prietto, L.; Hackbart, H.S.; Furlong, E.B. Antioxidant ctivity and enzyme inhibition of phenolic acids from fermented rice bran with fungus Rizhopusoryzae. Food Chem. 2014, 146, 371-377. [CrossRef] [PubMed]

23. Farahmandfar, R.; Asnaashari, M.; Sayyad, R. Comparison antioxidant activity of TaromMahali rice bran extracted from different extraction methods and its effect on canola oil stabilization. J. Food Sci. Technol. 2015, 52, 6385-6394. [CrossRef] [PubMed]

24. Wanyo, P.; Meeso, N.; Siriamornpun, S. Effects of different treatments on the antioxidant properties and phenolic compounds of rice bran and rice husk. Food Chem. 2015, 157, 457-463. [CrossRef] [PubMed]

25. Kim, S.; Lim, S. Enhanced antioxidant activity of rice bran extract by carbohydrase treatment. J. Cereal Sci. 2016, 68, 116-121. [CrossRef]

26. Liu, L.; Wen, W.; Zhang, R.F.; Wei, Z.C.; Deng, Y.Y.; Xiao, J.; Zhang, M.W. Complex enzyme hydrolysis releases antioxidative phenolics from rice bran. Food Chem. 2017, 214, 1-8. [CrossRef] [PubMed]

27. Zeng, Z.C.; Liu, C.M.; Luo, S.J.; Chen, J.; Gong, E.S. The Profile and Bioaccessibility of Phenolic compounds in cereals influenced by improved extrusion cooking treatment. PLoS ONE 2016, 11. [CrossRef] [PubMed]

28. Scaglioni, P.T.; Scaglioni, T.P.; Schmidt, C.G.; Badiale-Furlong, E. Availability of free and bound phenolic compounds in rice after hydrothermal treatment. J. Cereal Sci. 2014, 60, 526-532. [CrossRef]

29. Min, B.; McClung, A.; Chen, M.H. Effects of hydrothermal processes on antioxidants in rown, purple and red bran whole grain rice (Oryza sativa L.). Food Chem. 2014, 159, 106-115. [CrossRef] [PubMed] 
30. Chiremba, C.; Rooney, L.W.; Beta, T. Microwave-assisted extraction of bound phenolic acids in bran and flour fractions from sorghum and maize cultivars varying in hardness. J. Agric. Food Chem. 2012, 60, 4735-4742. [CrossRef] [PubMed]

31. Acosta-Estrada, B.A.; Gutiérrez-Uribe, J.A.; Serna-Saldivar, S.O. Bound phenolics in foods, a review. Food Chem. 2012, 152, 46-55. [CrossRef] [PubMed]

32. Wang, W.; Guo, J.; Zhang, J.Z.; Peng, J.; Liu, T.X.; Xin, Z.H. Isolation, identification and antioxidant activity of bound phenolic compounds present in rice bran. Food Chem. 2015, 171, 40-49. [CrossRef] [PubMed]

33. Bangoura, M.L.; Nsor-Atindana, J.; Zhou, H.M. Solvent optimization extraction of antioxidants from foxtail millet species' insoluble fibers and their free radical scavenging properties. Food Chem. 2013, 141, 736-744. [CrossRef] [PubMed]

34. Shao, Y.F.; Xu, F.F.; Sun, X.; Bao, J.S.; Beta, T. Identification and quantification of phenolic acids and anthocyanins as antioxidants in bran, embryo and endosperm of white, red and black rice kernels (Oryza sativa L.). J. Cereal Sci. 2014, 59, 211-218. [CrossRef]

35. Ti, H.H.; Zhang, R.F.; Zhang, M.W.; Wei, Z.C.; Chi, J.W.; Deng, Y.Y.; Zhang, Y. Effect of extrusion on phytochemical profiles in milled fractions of black rice. Food Chem. 2015, 178, 186-194. [CrossRef] [PubMed]

36. Guo, W.W.; Beta, T. Phenolic acid composition and antioxidant potential of insoluble and soluble dietary fiber extracts derived from select whole-grain cereals. Food Res. Int. 2013, 51, 518-525. [CrossRef]

37. Ajila, C.M.; Rao, U.J.S.P. Mango peel dietary fiber: Composition and associated bound phenolics. J. Funct. Foods 2013, 5, 444-450. [CrossRef]

38. Tao, B.B.; Ye, F.Y.; Li, H.; Hu, Q.; Xue, S.; Zhao, G.H. Phenolic profile and in vitro antioxidant capacity of insoluble dietary fiber powders from citrus (Citrus junos Sieb. ex Tanaka) pomace as affected by ultrafine grinding. J. Agric. Food Chem. 2014, 62, 7166-7173. [CrossRef] [PubMed]

39. Stalikas, C.D. Extraction, separation, and detection methods for phenolic acids and flavonoids. J. Sep. Sci. 2007, 30, 3268-3295. [CrossRef] [PubMed]

40. Shahidi, F.; Zhong, Y. Measurement of antioxidant activity. J. Funct. Foods 2015, 18, 757-781. [CrossRef]

41. Manach, C.; Williamson, G.; Morand, C.; Scalbert, A.; Remesy, C. Bioavailability and bioefficacy of polyphenols in humans. I. Review of 97 bioavailability studies. Am. J. Clin. Nutr. 2005, 81, 230S-242S. [PubMed]

42. Palafox-Carlos, H.; Ayala-Zavala, J.F.; González-Aguilar, G.A. The role of dietary fiber in the bioaccessibility and bioavailability of fruit and vegetable antioxidants. J. Food Sci. 2011, 76, R6-R15. [CrossRef] [PubMed]

43. Aydin, E.; Gocmen, D. The influences of drying method and metabisulfite pre-treatment on the color, functional properties and phenolic acids contents and bioaccessibility of pumpkin flour. LWT Food Sci. Technol. 2015, 60, 385-392. [CrossRef]

44. Kroon, P.A.; Faulds, C.B.; Ryden, P.; Robertson, J.A.; Williamson, G. Release of covalently bound ferulic acid from fiber in human colon. J. Agric. Food Chem. 1997, 45, 661-667. [CrossRef]

45. Zhao, Z.; Egashira, Y.; Sanada, H. Digestion and absorption of ferulic acid sugar esters in rat gastrointestinal tract. J. Agric. Food Chem. 2003, 51, 5534-5539. [CrossRef] [PubMed]

46. Saura-Calixto, F.; Serrano, J.; Goñi, I. Intake and bioaccessibility of total polyphenols in a whole diet. Food Chem. 2007, 101, 492-501. [CrossRef]

47. Chitindingu, K.; Benhura, M.A.N.; Muchuweti, M. In vitro bioaccessibility assessment of phenolic compounds from selected cereal grains: A prediction tool of nutritional efficiency. LWT Food Sci. Technol. 2015, 63, 575-581. [CrossRef]

48. Saura-Calixto, F. Concept and health-related properties of nonextractable polyphenols: The missing dietary polyphenols. J. Agric. Food Chem. 2012, 60, 11195-11200. [CrossRef] [PubMed]

49. Das, A.K.; Singh, V. Antioxidative free and bound phenolic constituents in pericarp, germ and endosperm of Indian dent (Zea mays var. indentata) and flint (Zea mays var. indurata) maize. J. Funct. Foods 2015, 13, 363-374.

50. Paiva, F.F.; Vanier, N.L.; Berrios, J.D.J.; Pan, J.; Villanova, F.A.; Gary, T.; Moacir, C.E. Physicochemical and nutritional properties of pigmented rice subjected to different degrees of milling. J. Food Compos. Anal. 2014, 35, 10-17. [CrossRef]

51. Finocchiaro, F.; Ferrari, B.; Gianinetti, A.; Dall'asta, C.; Galaverna, G.; Scazzina, F.; Pellegrini, N. Characterization of antioxidant compounds of red and white rice and changes in total antioxidant capacity during processing. Mol. Nutr. Food Res. 2007, 51, 1006-1019. [CrossRef] [PubMed] 
52. Dewanto, V.; Wu, X.; Adom, K.K.; Liu, R.H. Thermal processing enhances the nutritional value of tomatoes by increasing total antioxidant activity. J. Agric. Food Chem. 2002, 50, 3010-3014. [CrossRef] [PubMed]

53. Liu, L.; Guo, J.J.; Zhang, R.F.; Wei, Z.C.; Deng, Y.Y.; Guo, J.X.; Zhang, M.W. Effect of degree of milling on phenolic profiles and cellular antioxidant activity of whole brown rice. Food Chem. 2015, 185, 318-325. [CrossRef] [PubMed]

54. Benzie, I.F.F.; Strain, J.J. The ferric reducing ability of plasma (FRAP) as a measure of "antioxidant power": The FRAP assay. J. Clin. Sci. Res. 1996, 239, 70-76. [CrossRef] [PubMed]

55. Zhang, M.W.; Zhang, R.F.; Zhang, F.X.; Liu, R.H. Phenolic profiles and antioxidant activity of black rice bran of different commercially available varieties. J. Agric. Food Chem. 2010, 58, 7580-7587. [CrossRef] [PubMed]

56. Wolfe, K.L.; Liu, R.H. Cellular antioxidant activity (CAA) assay for assessing antioxidants, foods, and dietary supplements. J. Agric. Food Chem. 2007, 55, 8896-8907. [CrossRef] [PubMed]

57. Vitali, D.; Dragojevi, I.V.; Sebecic, B. Effects of incorporation of integral raw materials and dietary fiber on the selected nutritional and functional properties of biscuits. Food Chem. 2009, 114, 1462-1469. [CrossRef]

Sample Availability: Samples of the compounds are not available from the authors. 